\title{
Are dopamine-related genotypes risk factors for excessive gestational weight gain?
}

This article was published in the following Dove Press journal:

International Journal of Women's Health

18 May 2013

Number of times this article has been viewed

\author{
Gary S Goldfield ${ }^{1-5}$ \\ Lauren Marie Dowler ${ }^{5}$ \\ Mark Walker ${ }^{6,7}$ \\ Jameason D Cameron ${ }^{3}$ \\ Zachary M Ferraro' \\ Eric Doucet ${ }^{3}$ \\ Kristi B Adamo ${ }^{1-3}$ \\ 'Healthy Active Living and Obesity \\ Research Group, Children's Hospital \\ of Eastern Ontario Research Institute, \\ ${ }^{2}$ Department of Paediatrics, ${ }^{3} \mathrm{~S}$ chool \\ of Human Kinetics, ${ }^{4}$ School of \\ Psychology, University of Ottawa, \\ ${ }^{5}$ Department of Psychology, Carleton \\ University, ${ }^{6}$ Ottawa Hospital Research \\ Institute, ${ }^{7}$ Department of Obstetrics \\ and Gynecology, University of Ottawa, \\ Ottawa, ON, Canada
}

Background: Excessive gestational weight gain is associated with postpartum weight retention and downstream child obesity. Dopamine plays a critical role in the regulation of energy intake and body weight. The purpose of this study was to examine the relationship between excessive gestational weight gain and dopamine pathway-related polymorphisms, namely the variable nucleotide tandem repeat in the 3'untranslated region (UTR) region of the SLC6A3 (DAT-1) dopamine transporter gene and the 30-base pair variable nucleotide tandem repeat polymorphism of the $5^{\prime} \mathrm{UTR}$ of the monoamine oxidase-A $(M A O-A)$ gene.

Methods: Ninety-three women of mean age 31.7 \pm 4.2 years were recruited from the Ottawa and Kingston birth cohort and assessed at 12-20 weeks' gestation. Mean body mass index was $22.7 \pm 2.5 \mathrm{~kg} / \mathrm{m}^{2}$. Excessive gestational weight gain was defined according to the 2009 Institute of Medicine guidelines based on body mass index. Genotype analyses were performed using polymerase chain reaction and agarose gel electrophoresis.

Results: There was no relationship between the prevalence or magnitude of excessive gestational weight gain among women with the $3^{\prime}$ UTR single nucleotide polymorphism of the DAT-1 gene. However, 70\% (19 of 27) of women carrying the MAO-A 4/4 (high activity) allele exceeded recommendations for gestational weight gain compared with $48 \%$ ( 32 of 60 ) of those with the pooled $3 / 3,3 / 4$, and 3/3.5 (low activity) alleles $(P<0.05$ ). Similarly, those with the MAO-A 4/4 allele had significantly greater gestational weight gain than those with the $3 / 3,3 / 4$, or $3 / 3.5$ pooled genotypes $(19.3 \pm 4.1$ versus $17.0 \pm 5.0 \mathrm{~kg}$, $P=0.03)$.

Conclusion: Carriers of the $4 / 4$ variants of the $M A O-A$ gene may be at increased risk for excessive gestational weight gain.

Keywords: gestational weight gain, dopamine genes, monoamine oxidase-A

\section{Introduction}

The prevalence of overweight and obesity in children and adults in the US is quickly approaching an epidemic. ${ }^{1,2}$ This represents a serious public health concern given the adverse medical and psychosocial comorbidity of obesity in youth ${ }^{3,4}$ and adults. ${ }^{5}$ Pregnancy is considered a critical period for development of obesity in both mother and child, given that excessive gestational weight gain is associated with postpartum weight retention and maternal obesity after birth. ${ }^{6}$ Gestational weight gain is independently associated with a higher infant birth weight ${ }^{7}$ and a higher prevalence of downstream overweight and obesity in later childhood and beyond. ${ }^{8,9}$ In addition, there is growing evidence to suggest that meeting the Institute of Medicine's guidelines for gestational weight gain has a beneficial effect on downstream child obesity via minimizing high
Correspondence: Gary S Goldfield Healthy Active Living and Obesity Research Group, 40I Smyth Rd, Ottawa, ON Canada KIH 8LI Tel +I 6137377600 , ext 3288 Fax +16137384800

Email ggoldfield@cheo.on.ca 
birth weight. ${ }^{6}$ However, family and twin studies show that, in addition to environmental contributions, body mass index as well as weight gain over time resulting in obesity has a strong genetic component. ${ }^{10,11}$ Thus, identifying genetic determinants of excessive gestational weight gain can aid the development of prevention strategies by identifying highrisk populations with the goal of intervening to attenuate the intergenerational cycle of obesity.

There is considerable interest in the genetics of obesity and hyperphagia. ${ }^{12-14}$ Dopamine is a neurotransmitter that regulates our capacity to feel pleasure, including the motivation to obtain the rewarding properties of palatable food $^{15,16}$ and food intake, ${ }^{17}$ in part through the mesolimbic dopaminergic system. The dopamine transporter gene $D A T-1$ codes for a dopamine transporter protein (DAT) that is responsible for the reuptake of dopamine released into presynaptic terminals, thereby reducing the availability and level of dopamine at receptor sites. ${ }^{18}$ In particular, DAT is highly expressed in the human striatum (an integral part of the mesolimbic reward pathway) where it is a critical regulator of synaptic dopamine. The DAT-1 gene contains a variable number tandem repeat (VNTR) polymorphism in the $3^{\prime}$ region, and most humans carry the 9-repeat and 10-repeat forms. ${ }^{19}$ Although not conclusive, there is strong evidence to suggest that the DAT protein binding site density is elevated approximately $50 \%$ in carriers of the 10 -repeat VNTR over that of the 9-repeat allele, ${ }^{20,21}$ which could result in lower levels of postsynaptic dopamine as a result of heightened transportation and reuptake of dopamine back to the cell. Because dopamine is an important regulator of feeding, dopamine polymorphisms that alter postsynaptic dopamine availability may impact the rewarding value of food and food intake, consequently influencing energy balance.

Monoamine oxidase (MAO) is a mitochondrial enzyme involved in degrading biological amines, including dopamine, and thereby deaminates dopamine that has been taken back up into the synapse by the dopamine transporter, DAT-1. $M A O-A$, another gene in the dopamine pathway, was selected for this study because its promoter region contains a VNTR that influences gene transcription, it is considered to be a precursor of dopamine activity, and it is known to affect levels of dopamine availability. ${ }^{22}$ Deckert et $\mathrm{al}^{23}$ identified four common alleles, ie, the 3, 3.5, 4, and 5 30-base pair repeats, with the most common alleles being the 3-repeats and 4-repeats. The 4-repeat alleles have been associated with more efficient transcription than the 3 -repeat alleles, ${ }^{24}$ and so could be considered to be "highly active" alleles and have been shown to be associated with increased dopamine availability. ${ }^{25}$
To our knowledge, no study to date has examined the relationship between polymorphisms in the dopamine transporter gene (DAT-1) or $M A O-A$ gene, and gestational weight gain. Therefore, the purpose of this study was to assess the relationship between two dopamine pathway gene polymorphisms, ie, the dopamine transporter (DAT-1 9/9, 9/10 versus $10 / 10$ alleles) and the $M A O-A(3 / 3,3 / 4$, $3.5 / 3$ versus $4 / 4,4 / 5$ alleles), and gestational weight gain. Among the many reported polymorphisms reported for the dopamine metabolism genes, we have selected these because they are located in the regulatory regions $\left(5^{\prime} \mathrm{UTR} / 3^{\prime} \mathrm{UTR}\right)$ of the gene.

\section{Materials and methods Participants}

Ninety-three women of mean age $31.7 \pm 4.2$ years from the Ottawa and Kingston birth cohort were assessed at 12-20 weeks' gestation. Mean prepregnancy body mass index was $22.7 \pm 2.5 \mathrm{~kg} / \mathrm{m}^{2}$. Over $80 \%$ of the sample was Caucasian and virtually all had some post-secondary education, so the sample was relatively homogeneous and representative of a middle-to-high socioeconomic status demographic. Excessive gestational weight gain was defined according to the most recent 2009 Institute of Medicine guidelines on weight gain during pregnancy, ${ }^{26}$ which are based on pregravid body mass index. More specifically, the Institute of Medicine guidelines indicate that women who are classified as underweight based on a prepregnancy body mass index $<18.5$ should gain $12.5-18 \mathrm{~kg}(28-40 \mathrm{lb})$ during gestation. Women classified as normal weight based on a prepregnancy body mass index of 18.5-24.9 should gain $11.5-16 \mathrm{~kg}(25-35 \mathrm{lb})$. Women classified as overweight based on a body mass index of 25-29.9 should gain 7-11.5 kg (15-25 lb), while women classified as obese based on a prepregnancy body mass index of $\geq 30$ should gain $5-9 \mathrm{~kg}$ (11-20 lb). Total gestational weight gain was assessed by subtracting the initial self-reported prepregnancy weight from the final measured weight at delivery. Women from the Ottawa and Kingston birth cohort who exceeded gestational weight gain guidelines were compared with age-matched Ottawa and Kingston participants who met the guidelines. Exclusion criteria were smoking during pregnancy, medical conditions that could influence weight gain, such as prepregnancy or gestational diabetes, hypothyroidism, hyperthyroidism, Cushing's disease, inflammatory bowel disease, or celiac disease, as evaluated by a physician or registered nurse by interview or examination. Women who were taking medications that could affect their body composition and 
weight gain throughout gestation were also excluded. Women meeting the inclusion criteria and who gave informed consent for their blood/DNA samples to be used were selected. This resulted in a sample of 43 women who met the gestational weight gain recommendations during pregnancy and 50 being categorized as excessive weight gainers.

Informed written consent from each participant was obtained in accordance with the principles expressed in the Declaration of Helsinki guidelines for human subjects. The study was reviewed and approved by the research ethics boards of the Children's Hospital of Eastern Ontario and The Ottawa Hospital.

\section{Procedures}

Genomic DNA was extracted from whole blood using standard phenol extraction methods and purified using a FlexiGene DNA extraction kit (Qiagen, Valencia, CA). The VNTR polymorphism of the DAT-1 gene was amplified from the genomic DNA using polymerase chain reaction (PCR) with primers (Invitrogen, Carlsbad, CA) designed by Vandenbergh et al. ${ }^{19}$ The PCR was performed in a total volume of $27.5 \mu \mathrm{L}$ using $100 \mathrm{ng}$ of genomic DNA. The PCR mix included $2 \mu \mathrm{L}$ of $2.5 \mathrm{mM}$ dNTPs, $1.0 \mu \mathrm{L}$ each of $10 \mathrm{mM}$ forward and reverse primers, $5 \mu \mathrm{L}$ of PCR buffer (Qiagen), $5 \mu \mathrm{L}$ Q solution (Qiagen), and $0.25 \mu \mathrm{L} 5 \mathrm{U}$ Taq polymerase. The PCR conditions were optimized using a thermal cycler (GeneAmp PCR system 9700, Applied Biosystems, Foster City, CA) as follows: initial denaturation at $94^{\circ} \mathrm{C}$ for four minutes, followed by 30 cycles at $94^{\circ} \mathrm{C}$ for one minute, $60^{\circ} \mathrm{C}$ for one minute, and $72^{\circ} \mathrm{C}$ for one minute, with a final extension of five minutes at $72^{\circ} \mathrm{C}$. The $\mathrm{PCR}$ products were separated by electrophoresis using a $2 \%$ agarose gel and stained with ethidium bromide. Similarly the $M A O-A$ VNTR polymorphism was identified in an identical manner using primers designed by Jonsson et al 2000. ${ }^{25}$

Gels were then visualized under ultraviolet light and photographed using a Vilbert Lourmat system, and images were printed on a video graphic printer (UP-895MD, Sony Corporation, Tokyo, Japan) using both positive and negative contrast. Images of the gels were scanned at high resolution using an HPscanjet 8200 scanner, and were then genotyped visually by comparison with a molecular weight standard (GeneRuler) and the known amplification size of the PCR products.

\section{Statistical analysis}

Descriptive analyses comparing "normal" versus "excessive" weight gainers on age, prepregnancy weight and body mass index, and absolute weight gain were conducted using independent $t$-tests. Classification of the dopamine transporter (DAT-1) polymorphism first involved coding the alleles as $9 / 9(n=8)$ and $9 / 10(n=24)$ or $10 / 10(n=60)$ allele patterns. The one participant who had an allele pattern other than the $9 / 9,9 / 10$, or $10 / 10$ was dropped from the analysis. Analyses were performed combining the 9/9 and $9 / 10$ allele patterns together versus the $10 / 10$ allele pattern, thus comparing the participants for the presence or absence of the 9 allele genotype. Chi-square analyses were conducted to compare the prevalence of these dopamine allele patterns for "normal" versus "excessive" gestational weight gainers. Independent $t$-tests were also used to compare the amount of gestational weight gain by dopamine allele patterns.

The MAO-A allele pattern was categorized as $3 / 3$ $(\mathrm{n}=18), 3 / 4(\mathrm{n}=42), 4 / 4(\mathrm{n}=27)$, or $3 / 3.5(\mathrm{n}=2)$. Chi-square analyses were done to compare the prevalence of MAO-A alleles $(3 / 3+3 / 4+3 / 3.5$ versus $4 / 4)$ between "normal" and "excessive" weight gainers. Independent $t$-tests were also used to compare the amount of gestational weight gain according to MAO-A allele patterns.

Multiple regression analyses were conducted to ascertain the independent and interactive effects of the DAT-1 and MAO-A "at risk" allele patterns on the amount of gestational weight gain controlling for prepregnancy, body mass index, and age. All analyses were done using Statistical Package for Social Sciences version 19 software (SPSS Inc, Chicago, IL) with alpha preset at 0.05 .

\section{Results}

The mean age of the patients was $31.7 \pm 4.2$ years. Excessive and normal weight gainers did not differ significantly in age, but excessive gainers had a greater median (interquartile range) prepregnancy weight $(64.0[57.0,68.0] \mathrm{kg}$ versus 59.0 $[54.0,63.0] \mathrm{kg}, P<0.01)$, body mass index $(23.4$ [21.4, 26.0] versus 21.5 [20.3, 23.2], $P<0.01)$, and amount of weight gain throughout gestation $(20.0[18.8,23.0] \mathrm{kg}$ versus 13.6 $[12.2,15.0] \mathrm{kg}, P<0.001)$, as selected for in the initial selection of the sample.

Regarding DAT-1, Table 1 shows the percentage of each genotype observed for the sample. Chi-square analyses examining the pooled $9 / 9$ and $9 / 10$ versus the $10 / 10$ genotypes revealed no significant differences in the distribution of DAT-1 polymorphisms between normal and excessive gestational weight gainers $\left(\chi^{2}=0.00, P=1.00\right)$. More specifically, 53\% (17 of 32) of the excessive weight gainers had the $9 / 9$ or $9 / 10$ genotype, while $53 \%$ (32 of 60 ) had the $10 / 10$ allele. Similarly, $t$-tests revealed no differences 
Table I Characteristics of study sample stratified by gestational weight gain

\begin{tabular}{|c|c|c|c|}
\hline \multirow{2}{*}{\multicolumn{2}{|c|}{ Variables }} & \multicolumn{2}{|l|}{ Median (IQR) } \\
\hline & & $\begin{array}{l}\text { Normal } \\
(n=43)\end{array}$ & $\begin{array}{l}\text { Excessive } \\
(n=50)\end{array}$ \\
\hline \multicolumn{2}{|c|}{ Age (years) } & $32.0(29.0,35.0)$ & $31.0(27.0,34.0)$ \\
\hline \multicolumn{2}{|c|}{ Body mass index $\left(\mathrm{kg} / \mathrm{m}^{2}\right)^{*}$} & $21.5(20.3,23.2)$ & $23.4(21.4,26.0)$ \\
\hline \multicolumn{2}{|c|}{ Body weight $(\mathrm{kg})^{*}$} & $59.0(54.0,63.0)$ & $64.0(57.0,68.0)$ \\
\hline \multicolumn{2}{|c|}{ Gestational weight gain $(\mathrm{kg})^{* *}$} & $13.6(12.2,15.0)$ & $20.0(18.8,23.0)$ \\
\hline Genes & Genotype & n (\%) & n (\%) \\
\hline \multirow[t]{3}{*}{ DAT-I } & $9 / 9$ & $I(12.5)$ & $7(87.5)$ \\
\hline & $9 / 10$ & $14(58)$ & $10(42)$ \\
\hline & $10 / 10$ & $28(47)$ & $32(53)$ \\
\hline \multirow[t]{4}{*}{ MAO-A } & $3 / 3$ & $10(56)$ & $8(44)$ \\
\hline & $3 / 4$ & $22(52)$ & $20(48)$ \\
\hline & $3 / 3.5$ & $0(0)$ & $2(100)$ \\
\hline & $4 / 4$ & $8(30)$ & $19(70)$ \\
\hline
\end{tabular}

Notes: $* P<0.01$; $* * P<0.001$.

Abbreviation: IQR, interquartile range.

in gestational weight gain between individuals possessing the $9 / 9$ or $9 / 10$ genotypes and those with the $10 / 10$ genotype $(17.5 \pm 4.7 \mathrm{~kg}$ versus $17.5 \pm 4.9 \mathrm{~kg} ; t=[1,90]=-0.02$, $P=0.98)$.

Regarding $M A O-A$, Table 1 shows the distribution of VNTR genotypes in the sample Chi-square analyses examining the pooled $3 / 3,3 / 4$, and $3 / 3.5$ genotype versus the $4 / 4$ genotype revealed a significant difference in the distribution of the $M A O-A$ polymorphisms between normal and excessive gestational weight gainers $\left(\chi^{2}=4.9, P=0.04\right)$. More specifically, 70\% (19 of 27) of individuals with the 4/4 MAO-A genotype were excessive weight gainers compared with only $48 \%$ (30 of 62 ) of those with the pooled $3 / 3,3 / 4$, and $3 / 3.5$ genotypes. Similarly, $t$-tests revealed that those with the 4/4 genotype had significantly greater gestational weight gain than those with the pooled $3 / 3$, $3 / 4,3 / 3.5$ genotypes $(19.3 \pm 4.1 \mathrm{~kg}$ versus $17.0 \pm 5.0 \mathrm{~kg}$; $t=[1,87]=-2.192, P=0.03)$. Multiple regression analyses indicated that this significant relationship was maintained after controlling for prepregnancy body mass index and age (beta $=0.20, \mathrm{R}^{2}=0.14, P=0.006$ ). The $M A O-A$ by $D A T-1$ interaction effect on gestational weight gain was not significant.

\section{Discussion}

To the best of our knowledge, this is the first study to examine whether the allele patterns associated with altered dopamine availability from selective polymorphisms of the dopamine transporter (DAT-1) and $M A O-A$ genes would be associated with excessive gestational weight gain. There was no significant difference in prevalence of excessive gestational weight gain or magnitude of weight gain between the DAT-1 3' 40-base pair VNTR 9/9 and 9/10 genotypes compared with the 10/10 genotypes, although there was a trend toward more prevalent gestational weight gain among carriers of the 9/9 genotype (ie, seven of eight women), an effect that may have reached significance if the sample was larger. However, women with the $M A O-A$ promoter region VNTR allele pattern associated with increased dopamine activity (ie, the 4/4 genotype) gained significantly more weight during pregnancy than those with genotypes associated with "low activity" or reduced dopamine function (ie, pooled 3/3, 3/4, and 3/3.5 alleles). This relationship also remained significant after controlling for prepregnancy body mass index and age. In addition, a higher prevalence of women (70\%) having the allele pattern associated with increased dopamine activity (ie, 4/4) were classified as excessive weight gainers compared with $48 \%$ of subjects having the allele pattern associated with reduced dopamine function (pooled 3/3, 3/4, or 3/3.5 genotypes).

When interpreting our findings, it is important to note there are two different conceptualizations of how dopamine relates to feeding behavior, energy balance, and obesity. One paradigm suggests that those with higher available levels of dopamine, which mediates the rewarding value of food and other appetitive behaviors, ${ }^{15}$ tend to have a heightened sensitivity to reward, a greater hedonic capacity, and a stronger motivation to consume palatable foods that often results in overeating and obesity. ${ }^{27,28}$ This paradigm also suggests that a sluggish dopaminergic system with low availability of dopamine is associated with an anhedonic demeanor and a relative insensitivity to reward. ${ }^{27-29}$ Our results reflecting a significant relationship between the high active MAO-A (4/4) allele and gestational weight gain are consistent with this conceptualization. In addition, the highly active 4-repeat allele has been shown to be associated with greater rates of cigarette smoking, ${ }^{30}$ which is also consistent with this conceptualization. Although we did not find a relationship between DAT-1 and prevalence or magnitude of excessive gestational weight gain, other studies have found the 9-repeat alleles of DAT-1 were more prevalent among those with binge eating disorder. ${ }^{31}$ Additional evidence for this conceptualization comes from studies showing the DAT-1 gene moderates the response to a dopamine agonist whereby those with the 9-repeat alleles show greater reductions in appetite ratings and food intake. . $^{32,33}$

A competing conceptualization of how appetitive behaviors such as eating and substance abuse relate to 
dopamine availability is known as the reward deficiency syndrome, which is steadily growing in empirical support. The reward deficiency syndrome proposed by Blum et $\mathrm{al}^{34}$ and Noble et a ${ }^{35}$ was initially based on addiction research and more recently applied to obesity. ${ }^{36,37}$ This theory posits that increased drive to eat excessively leading to obesity has its roots in low levels of brain dopamine ${ }^{38}$ and these increased appetitive behaviors are methods of "self-medicating" to boost dopamine levels and compensate for a deficiency in the reward or pleasure one experiences. Although our current findings are not consistent with this theory, several studies have found that the DAT-1 10-repeat allele, which is associated with reduced dopamine availability via overactive transport, is associated with greater food intake and risk of obesity compared with those having the $9 / 9$ or $9 / 10$ repeat alleles. ${ }^{39,40}$ Stronger evidence for the reward deficiency syndrome comes from a series of large studies that found that the MAO-A 3 repeat alleles, which are considered to be lowactive with less dopamine availability, was associated with obesity in individuals ${ }^{22}$ and families ${ }^{41}$ and increased body mass index in men but not women. ${ }^{42,43}$ It is also important to note that two large epidemiological studies from the US did not find an association between the $M A O-A$ gene and body mass index, change in body mass index over time, ${ }^{44}$ or food intake. ${ }^{45}$ These inconsistent findings highlight the complexity of the gene-environment interaction, indicating that more research is needed to determine the role these dopamine gene variants play in energy intake, the reinforcing value of food, body weight, and weight gain among various populations.

\section{Strengths and limitations}

The strengths of this study include a novel research question, as well as using prepregnancy body mass index as a covariate given that overweight women are at increased risk of exceeding gestational weight gain guidelines. ${ }^{7}$ Several limitations also need to be acknowledged. First, given that this is the first study of its kind and included a relatively small sample size, its findings should be interpreted with caution because replication studies are needed. Moreover, due to resource limitations, we focused on two candidate genes in the dopamine pathway. However, we acknowledge that other polymorphic variants that influence dopamine function, such as various dopamine receptors (DRD2 and DRD4) and enzymes (COMT and MAO-B) have been shown to be associated with increased food reinforcement and intake, ${ }^{46}$ weight gain, ${ }^{47}$ and obesity ${ }^{22,48}$ and should be considered in future studies examining the influence of dopamine genes and gestational weight gain. In addition, our sample was quite homogeneous in that almost all women were Caucasian and had completed post-secondary education, so it is unclear how our findings would generalize to pregnant women of lower socioeconomic status or different race or ethnicity. Finally, given that some studies have shown an association between polymorphisms that alter the availability of synaptic dopamine and sensitivity to food reward and intake, ${ }^{45,49}$ it is assumed the mechanisms linking dopamine pathway polymorphisms and excessive gestational weight gain are mediated through energy intake. However, we did not measure energy intake throughout gestation and this limitation should be addressed in future research.

\section{Conclusion}

Although the present findings should be interpreted with caution, our data suggest that women who are carriers of the highly active $M A O-A$ gene variant (4/4 allele), which has been associated with increased post-synaptic dopamine availability, may be at higher risk of gestational weight gain. This is problematic because excessive gestational weight gain may predispose women to several untoward consequences, such as greater weight retention leading to maternal obesity post partum and increased risk of downstream child obesity and cardiometabolic complications. ${ }^{8,50-52}$ Given the health risks associated with gestational weight gain, it is suggested that this group of pregnant women who carry the high active MAO-A genotype would benefit from being targeted for lifestyle intervention during pregnancy, which a recent systematic review shows can be efficacious in minimizing gestational weight gain. ${ }^{53}$ Further studies are needed to replicate these findings in a larger sample, as well as address other aspects of the present study's limitations.

\section{Acknowledgments}

The authors would like to thank all the subjects who participated in the study and all the research staff who assisted with data collection. We would also like to thank Nancy Carson and Barron Gin from the Apoptosis Research Center at the Children's Hospital of Eastern Ontario for providing us with laboratory space and equipment and for overseeing the genotyping process. At the time the study was conducted, GSG, MW, and ED were supported by new investigator awards from the Canadian Institutes of Health Research. JDC was supported by a University of Ottawa graduate scholarship. ZMF was supported by an Ontario Graduate Scholarship. KBA and GG held a Canadian Foundation of Innovation Award to equip the laboratory at the Children's 
Hospital of Eastern Ontario Research Institute where the study was conducted.

\section{Disclosure}

The authors report no conflicts of interest in this work.

\section{References}

1. Roberts KC, Shields M, de Groh M, Aziz A, Gilbert, JA. Overweight and obesity in children and adolescents: results from the 2009 to 2011 Canadian Health Measures Survey. Health Rep. 2012;23:37-41.

2. Hedley AA, Ogden CL, Johnson CL, Carroll MD, Curtin LR, Flegal KM. Prevalence of overweight and obesity among US children, adolescents, and adults, 1999-2002. JAMA. 2004;291:2847-2850.

3. Freedman DS, Dietz WH, Srinivasan SR, Berensen, GS. The relation of overweight to cardiovascular risk factors among children and adolescents: the Bogalusa Heart Study. Pediatrics. 1999;103:1175-1182.

4. Ebbeling CB, Pawlak DB, Ludwig DS. Childhood obesity: public-health crisis, common sense cure. Lancet. 2002;360:473-482.

5. Mokdad A, Serdula MK, Dietz WH, Bowman, BA, Marks JS, Koplan JP. The spread of the obesity epidemic in the United States. JAMA. 1999;282:1519-1522.

6. Vesco K, Dietz P, Rizzo J, et al. Excessive gestational weight gain and postpartum weight retention among obese women. Obstet Gynecol. 2009;114:1069-1075.

7. Ferraro ZM, Barrowman N, Prud'homme D, et al. Excessive gestational weight gain predicts large for gestational age neonates independent of maternal body mass. J Matern Fetal Neonatal Med. 2012;25: $538-542$.

8. Oken E. Excess gestational weight gain amplifies risks among obese mothers. Epidemiology. 2009;20:82-83.

9. Yu Z, Han S, Zhu G, et al. Birth weight and subsequent risk of obesity: a systematic review and meta-analysis. Obes Rev. 2011;12:525-542.

10. Maes H, Neale M, Eaves L. Genetic and environmental factors in relative body weight and human adiposity. Behav Genet. 1997;27:325-351.

11. Stunkard AJ, Harris JR, Pedersen NL, McClearn GE. The body mass index of twins who have reared apart. N Engl J Med. 1990;322:1483-1487.

12. Allison DB, Kaprio J, Korkeila M, Koskenvuo M, Neale MC, Hayakawa K. The heritability of body mass index among an international sample of monozygotic twins reared apart. Int $J$ Obes Relat Metab Disord. 1996;20:501-506.

13. Rankinen T, Bouchard C. Genetics of food intake and eating behavior phenotypes in humans. Annu Rev Nutr. 2006;26:413-434.

14. Rankinen T, Zuberi A, Chagnon YC, et al. The human obesity gene map: the 2005 update. Obesity (Silver Spring). 2006;14:529-644.

15. Berridge $\mathrm{KC}$, Robinson TE. What is the role of dopamine in reward: hedonic impact, reward learning, or incentive salience? Brain Res Brain Res Rev. 1998;28:309-369.

16. Martel P, Fantino M. Mesolimbic dopaminergic system activity as a function of food reward: a microdialysis study. Pharmacol Biochem Behav. 1996;53:221-226.

17. Epstein LH, Saelens BE. Behavioral economics of obesity: food intake and energy expenditure. In: Bickel WK, Vuchinich RE, editors. Reframing Health Behavior Change with Behavioral Economics. Mahwah, NJ: Lawrence Erlbaum; 2000.

18. Bannon MJ, Granneman JG, Kapatos G. The dopamine transporter: potential involvement in neuropsychiatric disorders. In: Bloom FE, Kupfer DJ, editors. Psychopharmacology: The Fourth Generation of Progress. New York, NY: Raven Press; 1995.

19. Vandenbergh D, Perisco A, Hawkins A, et al. Human dopamine transporter gene (DAT 1) maps to chromosome 5p15.3 and displays a VNTR. Genomics. 1992;14:1104-1106.

20. Fuke S, Suo S, Takahashi N, Koike H, Sasagana N, Ishiura S. The VNTR polymorphism of the human dopamine transporter (DAT1) gene affects gene expression. Pharmacogenomics J. 2001;1:152-156.
21. VanNess S, Owens M, Kilts C. The variable number of tandem repeats element in DAT 1 regulates in vitro dopamine transporter density. $B M C$ Genetics. 2005;6:55.

22. Need AC, Ahmadi KR, Spector TD, Goldstein DB. Obesity is associated with genetic variants that alter dopamine availability. Ann Hum Genet. 2006;70:293-303.

23. Deckert J, Catalano M, Syagailo YV, et al. Excess of high activity monoamine oxidase A gene promoter alleles in female patients with panic disorder. Hum Mol Genet. 1999;8:621-624.

24. Sabol SZ, Hu S, Hamer D. A functional polymorphism in the monoamine oxidase A gene promoter. Hum Genet. 1998;103:273-279.

25. Jonsson EG, Norton N, Gustavsson JP, Oreland L, Owen MJ, Sedvall GC. A promoter polymorphism in the monoamine oxidase A gene and its relationships to monoamine metabolite concentrations in CSF of healthy volunteers. $J$ Psychiatr Res. 2000;34:239-244.

26. Institute of Medicine. Weight Gain During Pregnancy: Reexamining the Guidelines. Washington, DC: The National Academic Press; 2009.

27. Davis C, Patte K, Levitan R, Reid C, Tweed S, Curtis C. From motivation to behaviour: a model of reward sensitivity, overeating, and food preferences in the risk profile for obesity. Appetite. 2007;48:12-19.

28. Franken $\mathrm{IH}$, Muris $\mathrm{P}$. Individual differences in reward sensitivity are related to food craving and relative body weight in healthy women. Appetite. 2005;45:198-201.

29. Depue RA, Collins PF. Neurobiology of the structure of personality: dopamine, facilitation of incentive motivation, and extraversion. Behav Brain Sci. 1999;22:491-517.

30. Wiesbeck GA, Wodarz N, Weijers HG, et al. A functional polymorphism in the promoter region of the monoamine oxidase A gene is associated with the cigarette smoking quantity in alcohol-dependent heavy smokers. Neuropsychobiology. 2006;53:181-185.

31. Shinohara M, Mizushima H, Hirano M, et al. Eating disorders with binge-eating behaviour are associated with the s allele of the 3'-UTR VNTR polymorphism of the dopamine transporter. J Psychiatry Neurosci. 2004;29:134-137.

32. Davis C, Levitan RD, Kaplan AS, et al. Dopamine transporter gene (DAT1) associated with appetite suppression to methylphenidate in a case-control study of binge eating disorder. Neuropsychopharmacology. 2007;32:2199-2206.

33. Leddy JJ, Waxmonsky JG, Salis RJ, et al. Dopamine-related genotypes and the dose-response effect of methylphenidate on eating in attentiondeficit/hyperactivity disorder youths. J Child Adolesc Psychopharmacol. 2009;19:127-136.

34. Blum K, Braverman ER, Wood RC, et al. Increased prevalence of the Taq I A1 allele of the dopamine receptor gene (DRD2) in obesity with comorbid substance use disorder: a preliminary report. Pharmacogenetics. 1996;6:297-305.

35. Noble EP, St Jeor ST, Ritchie T, et al. D2 dopamine receptor gene and cigarette smoking: a reward gene? Med Hypotheses. 1994;42: 257-260.

36. Wang GJ, Volkow ND, Logan J, et al. Brain dopamine and obesity. Lancet. 2001;357:354-357.

37. Wang GJ, Volkow ND, Fowler JS. The role of dopamine in motivation for food in humans: implications for obesity. Expert Opin Ther Targets. 2002;6:601-609.

38. Volkow ND, Wise RA. How can drug addiction help us understand obesity? Nat Neurosci. 2005;8:555-560.

39. Agurs-Collins T, Fuemmeler BF. Dopamine polymorphisms and depressive symptoms predict foods intake. Results from a nationally representative sample. Appetite. 2011;57:339-348.

40. Epstein LH, Jaroni JL, Paluch RA, et al. Dopamine transporter genotype as a risk factor for obesity in African-American smokers. Obes Res. 2002;10:1232-1240.

41. Camarena B, Santiago H, Aguilar A, Ruvinskis E, GonzalezBarranco J, Nicolini H. Family-based association study between the monoamine oxidase A gene and obesity: implications for psychopharmacogenetic studies. Neuropsychobiology. 2004;49: 126-129. 
42. Ducci F, Newman TK, Funt S, Brown GL, Virkkunen M, Goldman D. A functional polymorphism in the MAOA gene promoter (MAOALPR) predicts central dopamine function and body mass index. Mol Psychiatry. 2006;11:858-866.

43. Fuemmeler BF, Agurs-Collins TD, McClernon FJ, et al. Genes implicated in serotonergic and dopaminergic functioning predict BMI categories. Obesity (Silver Spring). 2008;16:348-355.

44. Gallicchio L, Chang HH, Christo DK, et al. Single nucleotide polymorphisms in obesity-related genes and all-cause and causespecific mortality: a prospective cohort study. BMC Med Genet. 2009; $10: 103$.

45. Agurs-Collins T, Fuemmeler BF. Dopamine polymorphisms and depressive symptoms predict foods intake. Results from a nationally representative sample. Appetite. 2011;57:339-348.

46. Epstein LH, Wright SM, Paluch RA, et al. The relationship between food reinforcement and dopamine genotypes on food intake in smokers. Am J Clin Nutr. 2004;80:82-88.

47. Stice E, Yokum S, Bohon C, Marti N, Smolen A. Reward circuitry responsivity to food predicts future increases in body mass: moderating effects of DRD2 and DRD4. Neuroimage. 2010;50:1618-1625.
48. Shield AJ, Thomae BA, Eckloff BW, Wieben ED, Weinshilbourn RM. Human catechol O-methyltransferase genetic variation: gene resequencing and functional characterization of variant allozymes. Mol Psychiatry. 2004;9:151-160.

49. Epstein LH, Temple JL, Neaderhiser BJ, Salis RJ, Erbe RW, Leddy JJ. Food reinforcement, the dopamine D2 receptor genotype, and energy intake in obese and nonobese humans. Behav Neurosci. 2007;121: $877-886$.

50. Adamo KB, Ferraro, ZM, Brett KE. Pregnancy is a critical period for prevention of obesity and cardiometabolic risk. Canadian Journal of Diabetes. 2012;36:133-141.

51. Oken E, Taveras EM, Kleinman KP, Rich-Edwards JW, Gillman MW. Gestational weight gain and child adiposity at age 3 years. Am J Obstet Gynecol. 2007;196:322-328.

52. Fraser A, Tilling K, Donald-Wallis C, et al. Association of maternal weight gain in pregnancy with offspring obesity and metabolic and vascular traits in childhood. Circulation. 2010;121:2557-2564.

53. Sui Z, Grivell RM, Dodd JM. Antenatal exercise to improve outcomes in overweight or obese women: a systematic review. Acta Obstet Gynecol Scand. 2012;91:538-545.
International Journal of Women's Health

\section{Publish your work in this journal}

The International Journal of Women's Health is an international, peerreviewed open-access journal publishing original research, reports, editorials, reviews and commentaries on all aspects of women's healthcare including gynecology, obstetrics, and breast cancer. The manuscript management system is completely online and includes

\section{Dovepress}

a very quick and fair peer-review system, which is all easy to use. Visit http://www.dovepress.com/testimonials.php to read real quotes from published authors.

\footnotetext{
Submit your manuscript here: http://www.dovepress.com/international-journal-of-womens-health-journal
} 